\title{
Violencia hacia las mujeres y presunción de inocencia
}

\section{Violence against women and presumption of innocence}

\author{
Ilsse Carolina Torres Ortega \\ Instituto Tecnológico y de Estudios Superiores de Occidente \\ ORCID ID 0000-0002-5929-9137 \\ torresilsse@iteso.mx
}

\author{
Cita recomendada: \\ Torres Ortega, I. C. (2021). Violencia hacia las mujeres y presunción de inocencia. Eunomía. Revista en \\ Cultura de la Legalidad, 20, pp. 155-171. \\ doi: https://doi.org/10.20318/eunomia.2021.6067
}

Recibido / received: 28/08/2020

Aceptado / accepted: 10/03/2021

\begin{abstract}
Resumen
En el presente documento, se explora la acusación de que las reivindicaciones a favor de las mujeres tienen un tinte punitivo, en el sentido de que pretenden combatir los estereotipos de género a través de los medios más coercitivos del Estado, exigiendo, además, que este restrinja los derechos individuales de los procesados para lograr más castigos y más severidad en ellos. Desde el contexto mexicano, se analiza si, en efecto, las pretensiones a favor de las mujeres implican el debilitamiento de garantías, específicamente, de una tan importante como la derivada de la protección del derecho de presunción de inocencia de los individuos sujetos a un proceso penal por delitos que implican violencia hacia las mujeres.
\end{abstract}

\section{Palabras clave}

Violencia, violencia hacia las mujeres, feminismo, presunción de inocencia, proceso penal.

\begin{abstract}
In this document, the text analyzes the allegations against the punitive nature of vindications in favor of women. The argument runs that to combat gender stereotypes feminism intends to use the most coercive means of the State, including restrictions of the defendant's rights so to raise the number of punishments and to increase its severity. From the mexican context, the text studies whether the claims in favor of women necessarily imply the weakening of guarantees, undermining particularly the presumption of innocence of those who have been accused of crimes of violence against women.
\end{abstract}

\section{Keywords}

Violence, violence against women, feminism, presumption of innocence, criminal process. 
SUMARIO. 1. Introducción. 2. Impunidad. 3. La falsa oposición entre los derechos de los procesados -o de los condenados- y los derechos de las víctimas. 4. La presunción de inocencia y el estatus de víctima de las mujeres. 5. Conclusiones.

\section{Introducción}

A día de hoy, la relación entre el Derecho y la perspectiva de género sigue generando profundos interrogantes. Aunque discursivamente el género parece ocupar un espacio cada vez más importante en las agendas políticas, en nuestras comunidades político-jurídicas persisten situaciones que ponen en duda que haya plena consciencia sobre cómo el género coloca a los individuos en situaciones de desigualdad. No es ninguna osadía, entonces, señalar que continúa siendo necesario esclarecer a qué nos referimos cuando aseveramos la posibilidad -y la pertinenciade que exista una perspectiva de género, así como edificar intersubjetivamente cómo esta se proyecta en actividades concretas, por ejemplo, en las funciones básicas del Derecho.

A estas dificultades de tipo cognitivo - ¿qué es?, ¿cómo se satisface?, ¿cómo se traduce en las distintas actividades jurídicas?, etc.- hay que añadir otras dificultades que tienen que ver con factores subjetivos; por ejemplo, la resistencia a revisar críticamente ciertos postulados asumidos en torno al género o una actitud escéptica respecto a que esta sea una categoría relevante para el Derecho. Estas últimas dificultades tienen que ver -por eso las denomino subjetivas, en el sentido de relativas al sujeto- con estados mentales del agente que constituyen motivos y corresponde entender y conocer en tanto que dotan de sentido a las acciones $u$ omisiones de las personas ${ }^{1}$. Estos motivos, vistos como razones explicativas de la acción, se configuran a través de emociones, intereses, creencias, evaluaciones y deseos que, aun cuando forman parte de la personalidad de un individuo, no quiere decir que sean rasgos inalterables. Precisamente una característica de la agencia es la posibilidad -y también el deber- de revisar si nuestras creencias y evaluaciones son racionales, en el sentido de si están o no justificadas ${ }^{2}$.

Todas estas dificultades tienen como consecuencia, en muchas ocasiones, la incomprensión. Pero, sucede que la falta de entendimiento respecto a las reivindicaciones de la perspectiva de género se ha recrudecido, precisamente, en aquellas que más visibilidad requieren. Es así como las perspectivas feministas, por ejemplo, constantemente ven cuestionada la legitimidad de los intereses que defienden, colocándoseles etiquetas peyorativas, que bien pueden ser producto de la incomprensión, pero cuyo resultado es la perpetuación de una forma de mirar a

\footnotetext{
${ }^{1}$ De ahí, por ejemplo, la discusión sobre la conveniencia de castigar más severamente los delitos cometidos por ciertos motivos, por ejemplo, el odio. Sobre esta cuestión y los problemas que plantea en relación con los postulados del Derecho penal liberal que proscriben castigar a alguien por sus rasgos de carácter, ver el trabajo de Laura Manrique (2019).

2 En este sentido, González Lagier señala que «la irracionalidad de una creencia puede deberse a) a la ausencia de razones suficientes para creer (creencias dogmáticas); $b$ ) a que se derive a partir de una creencia a su vez injustificada, y c) a que se base en una presunción y regla de fiabilidad inadecuada» $(2009,111)$. Evidentemente, el entramado de estados mentales es complejo y se mezclan creencias racionales e irracionales; parafraseando un ejemplo que aporta el mismo autor, en el caso de una persona con sentimientos machistas, el odio que siente por $X$ tiene su origen no solo en la creencia de que $X$ es de un determinado género -la cual puede ser una creencia justificada-, sino también en determinadas creencias y juicios sobre ese género y sobre las diferencias de género en general -las cuales no están justificadas- $(2009,112)$.
} 
mujeres y a hombres que implica una desigualdad sin más fundamento -esto es, ninguno- que la tradición de la división de nuestro lugar en el espacio y en las dinámicas públicas y privadas, atendiendo a cuál sea nuestro sexo. Y esto que afecta a mujeres y a hombres suele suponer, especialmente en el caso de las mujeres, una limitación en el ejercicio real de sus derechos.

Si bien no es posible negar que, al menos formalmente, existe la intención estatal de garantizar las libertades y derechos de las mujeres ${ }^{3}$, hay que recordar la advertencia de Norberto Bobbio respecto a que ciertos derechos pueden estar siendo tan solo expresiones de aspiraciones ideales, en tanto que hay una diferencia fundamental entre proclamar un derecho y satisfacerlo efectivamente: «El lenguaje de los derechos tiene sin duda una gran función práctica, que es la de dar particular fuerza a las reivindicaciones de los movimientos que exigen para sí y para los demás la satisfacción de nuevas necesidades materiales y morales, pero se convierte en engañosa si oscurece u oculta la diferencia entre el derecho reivindicado y el reconocido y protegido» (Bobbio, 1991, p. 22). Las perspectivas feministas han venido exigiendo el cumplimiento de ambas dimensiones de los derechos de las mujeres, al tiempo que han intentado también reducir la incomprensión y lograr un cambio social profundo en las relaciones entre los géneros.

Este trabajo pretende analizar una posición que resulta del inadecuado entendimiento de los intereses de las mujeres. Me refiero a la acusación de que el feminismo es irracional y punitivo, pretendiendo no solo que los estereotipos de género sean combatidos a través de los medios más coercitivos del Estado, sino, además, exigiendo que este restrinja los derechos individuales básicos de los procesados para lograr más castigos y más severidad en ellos. En lo que sigue exploraré si, efectivamente, las reivindicaciones a favor de las mujeres implican de alguna forma el debilitamiento de garantías, específicamente, de una tan importante como lo es el derecho de presunción de inocencia de los individuos sujetos a un proceso penal por delitos que implican violencia hacia las mujeres.

Para llevar a cabo lo anterior voy a realizar el siguiente recorrido. En primer lugar, revisaré brevemente cómo el vivir en un contexto de impunidad nos coloca en una situación de vulnerabilidad respecto a la posibilidad de padecer un daño y de no vernos respaldados en caso de sufrirlo, la cual tiene consecuencias especialmente perniciosas para las mujeres. Es necesario señalar que, para ello, tomaré como ejemplo el caso mexicano. Con lo anterior pretendo sostener que la violencia y la impunidad hacia el daño que sufren las mujeres están en el trasfondo de las preocupaciones del feminismo. En segundo lugar, abordaré cómo estas reivindicaciones legítimas pueden verse afectadas por el paralogismo de la falsa oposición, el cual tiene como consecuencia generar planteamientos falaces; por ejemplo, la aparente dicotomía entre los derechos de las víctimas y los derechos de quienes están siendo procesados o de quienes han sido condenados. Entre estas falsas dicotomías, me centraré en aquella que sostiene que respetar la presunción de inocencia es un obstáculo para el proceso penal en delitos de violencia hacia las mujeres o, incluso, que dicha presunción es una ventaja injustificada para aquel que está siendo investigado. En este orden de ideas, en tercer lugar, analizaré el derecho de presunción de inocencia para señalar las distintas dimensiones reconocidas jurisprudencialmente a este derecho - de nuevo, en el contexto mexicano- y también para mostrar cómo, en realidad, no estamos ante una genuina presunción. Esto último

\footnotetext{
${ }^{3}$ Una gran cantidad de Estados se han comprometido de muchas maneras a combatir la discriminación de las mujeres. Como muestra de ello, los múltiples tratados y convenciones internacionales sobre la materia como la Convention on the Elimination of All Forms of Discrimination against Women (CEDAW), la Declaration of the Elimination of Violence against Women (DEVAW) y la Convención Interamericana para Prevenir, Sancionar y Erradicar la Violencia contra la Mujer.
} 
me llevará a examinar cómo parte de la sostenida oposición puede proceder del falso carácter presuntivo de la inocencia, ya que su fundamento no es empírico, sino una cuestión normativa que atiende a fines y valores. La presunción de inocencia, como se sostendrá, destaca por ser un principio que fundamenta el Derecho penal, en tanto que establece una pauta de justicia sobre la distribución del error: es mejor declarar inocente a un culpable que condenar a un inocente. Esto, sin embargo, no significa que la presunción de inocencia no pueda ser -o esté siendo- utilizada de forma espuria para invisibilizar las exigencias de las mujeres. $Y$ es que, en casos de violencia hacia estas, el Estado violenta institucionalmente de manera omisiva cuando ignora la situación de vulnerabilidad de las mujeres, cuando no emite las medidas de protección adecuadas para ellas, cuando cuestiona y dificulta el proceso de denuncia y de seguimiento del proceso penal. En estos casos, como se puede observar, en realidad no se trata de dos grupos de derechos que se oponen, sino de que el segundo grupo -el de las mujeres- es ignorado. Finalmente, voy a sostener que muchas reivindicaciones feministas están vinculadas con esto último y que, por tanto, es injusto calificar de irracionales a estas perspectivas. Es preciso, pues, liberarse de algunos prejuicios que nos colocan en frontal oposición con las pretensiones de un movimiento que, pese a su variedad, trata precisamente de hacer imperar la fuerza de la razón frente a la ceguera de los prejuicios. Pero para que esto suceda, para dar el paso adecuado, la razón imparcial ha de ser alcanzada al modo en que subrayan -y nos recuerdan- las palabras de Adela Cortina cuando habla de la razón práctica:

...solo una razón com-pasiva o com-padeciente, puesta en pie por la vivencia del sufrimiento, espoleada por el ansia de felicidad, asombrada por el absurdo de la injusticia, tiene fuerza suficiente para desentrañar la lógica que corre por las venas de este misterioso ámbito, sin contentarse con cualquier aparente justificación (2000, p. 20).

\section{Impunidad y violencia}

Es prácticamente un lugar común la afirmación de que en algunos países sus habitantes padecen un exceso de violencia. Pero, sucede que, además de estar siendo severamente dañados, en estos países suele haber también una crisis de impunidad y de ineficiencia del sistema de justicia para atender esta situación.

Por ejemplo, revisemos el caso mexicano. De acuerdo con los resultados más recientes de la Encuesta Nacional de Victimización y Percepción sobre Seguridad Pública en México (ENVIPE) ${ }^{4}$, en el año 2018 se estimó un total de 24.7 millones de víctimas de 18 años y más, representando una tasa de 28,269 víctimas por cada 100,000 habitantes (Encuesta Nacional de Victimización y Percepción sobre Seguridad Pública en México [ENVIPE], 2021, p.7). De esa estimación, sin embargo, se denunció solo el $10.6 \%$ de los delitos ocurridos. Entre las razones para no denunciar destacan que se considera una pérdida de tiempo, la desconfianza en la autoridad y su actitud hostil. Esto quiere decir que el $93.2 \%$ de los daños sufridos por la población mexicana han quedado institucionalmente impunes. Del $10.6 \%$ en donde esto no ocurrió, se inició una averiguación previa -según el anterior sistema de justicia penal- o una carpeta de investigación en el $63.9 \%$ de los casos; es decir, tan solo en el $6.8 \%$. Ahora bien, del total de las averiguaciones o carpetas de investigación, en el $51.1 \%$ de los casos no ocurrió nada o no se continuó con la investigación (ENVIPE, 2019, p. 31). Esta información esclarece el alcance de la crisis de impunidad en este país. Objetivamente los habitantes de México tienen una probabilidad muy alta de

\footnotetext{
4 Consultable aquí: https://www.inegi.org.mx/contenidos/programas/envipe/2019/doc/envipe2019 presentacion nacional.pdf
} 
sufrir un daño en sus bienes y de que dicho daño no sea reconocido, investigado y reparado.

Los datos también nos proporcionan información útil sobre el sexo de quién ejerce y quién recibe la violencia. Los hombres son las principales víctimas en casi todos los delitos. Sin embargo, en delitos concretos las mujeres son más propensas a serlo. Por ejemplo, en el caso de los delitos sexuales, por cada delito sexual cometido a un hombre se cometen once a mujeres (ENVIPE, 2019, p.14).

Los hombres son los principales sujetos pasivos de delitos violentos y también parece ser un hecho que los hombres son los principales ejecutores de esa violencia. Por ejemplo, tomando como referencia a la población penitenciaria, de acuerdo con el Censo Nacional de Gobierno, Seguridad Pública y Sistema Penitenciario Estatales (CNGSSPE) ${ }^{5}$, en el año 2018 ingresaron a los centros penitenciarios de este país un total de 101,512 personas, de las cuales el $92.6 \%$ son hombres responsabilizados, principalmente, por delitos de robo, narcomenudeo, homicidio, violación y secuestro (Censo Nacional de Gobierno, Seguridad Pública y Sistema Penitenciario Estatales [CNGSSPE], 2019, p. 30).

Ahora bien, con esta información no pretendo sostener nada más allá de que la información estadística se orienta a mostrar que, tal y como sostiene Francesca Poggi al identificar distintas formas en las que un acto violento puede asociarse al género $^{6}$, la violencia forma parte de un estereotipo de género asociado a la masculinidad. Antes de proseguir, es necesario tener presente la distinción que ha elaborado Federico Arena $-\mathrm{y}$ que es también recogida por Poggi- entre los estereotipos descriptivos y los estereotipos normativos. Pese a la carga emotiva negativa del término, los estereotipos descriptivos ofrecen información sobre el mundo, por lo que pueden ser epistemológicamente útiles y deben ser evaluados en función de su correspondencia con las propiedades reales del grupo al que se refieren -si tienen base estadística serán estereotipos descriptivos que nos dicen algo acerca del mundo y nos permiten predecir ciertos estados de cosas; de otra forma, serán estereotipos falsos-. Por su parte, los estereotipos normativos establecen una relación de deber ser entre la conducta asociada a un grupo específico y el ser un miembro de tal grupo; establecen que un individuo con determinadas características debe llevar a cabo ciertas tareas o asumir determinados roles sociales (Arena, 2016, p. 55). Teniendo en cuenta lo anterior, entonces, es posible afirmar que en términos estadísticos -esto es, lo que conforma la sustanciación de un estereotipo descriptivolos hombres llevan a cabo más delitos violentos que las mujeres y que, en consecuencia, es más probable que un hombre cometa un delito de esta naturaleza.

Sin embargo, de lo anterior no es adecuado inferir una correlación normativa entre la violencia y la masculinidad, igual que tampoco lo es extralimitarse en el uso predictivo del estereotipo. Esto es, si bien este uso puede ser valioso en el contexto de las investigaciones penales, en el sentido de que nos autoriza a tener presente que es más probable que en determinados delitos -por ejemplo, los delitos de violencia hacia las mujeres- el autor sea un hombre, esto no implica presumir que, si el acusado es un hombre, entonces, es culpable (Poggi, 2019, p. 297). La presunción

\footnotetext{
${ }^{5}$ Consultable aquí: https://www.inegi.org.mx/contenidos/programas/cngspspe/2019/doc/cngspspe 2019 resultados.pdf.

${ }^{6}$ Poggi sostiene que en la literatura no existe una noción unitaria y clara de la violencia de género. Para avanzar en esta tarea, identifica distintos sentidos en los que la violencia se asocia el género: (1) la violencia como estereotipo de género; (2) la violencia motivada por cuestiones de género; y (3) la violencia basada en estereotipos de género -que incluye dos criterios: la violencia que afecta a las mujeres de manera desproporcionada -criterio cuantitativo- y la violencia dirigida contra una mujer por el solo hecho de serlo - criterio ideológico- (2019, pp. 294-305).
} 
de inocencia establece, en este caso, un límite normativo -no debe considerarse a alguien culpable con base en un estereotipo de género por mucho sustrato que tenga en un porcentaje estadístico, ya que hacerlo sería dar un salto del nivel de la estadística al nivel de la naturaleza o de las propiedades del individuo en concreto-, pero también un límite por razones epistemológicas -no se puede considerar a alguien culpable porque el estereotipo, aun teniendo base estadística, no deja de ser una inducción sustentada en la probabilidad, no en la certeza.

Ahora bien, pese a la importancia de este límite, no hay que olvidar que la perspectiva de género pretende visibilizar las estructuras de dominación que subyacen a los procesos de justicia. Esto quiere decir que, en casos de violencia hacia las mujeres, junto a la advertencia de no sobrepasar el uso predictivo del estereotipo, también hay que hacer la advertencia de no invalidar o invisibilizar el sustento estadístico de dicho estereotipo, además de no pasar por alto cómo esta invalidación resulta, precisamente, de la existencia de estereotipos normativos sobre las mujeres. Así, ignorar en nombre de la presunción de inocencia el soporte estadístico de que, en determinados tipos de violencias las víctimas suelen ser mujeres y los victimarios hombres es una forma de mantener la desigualdad en las relaciones de poder en el marco del sistema de justicia. Tal y como indica Gema Fernández, es necesario hacer manifiesto que los estereotipos de género socaban el derecho de las mujeres a vivir libres de violencia de distintas maneras; entre ellas (1) al legitimar el uso de la violencia en mujeres que no cumplen la normatividad sexual y de género -por ejemplo, la violación de mujeres lesbianas como método de corrección-; (2) al influenciar la manera en que son tratadas por el sistema judicial -por ejemplo, la falta de investigación en casos de violencia ejercida hacia las mujeres porque estas vestían de manera inapropiada o porque habían salido de noche-; o (3) creando obstáculos para aquellas que buscan formas de salir de la violencia -por ejemplo, al desconocer el peso de las responsabilidades sobre el cuidado familiar cuando hay dependencia económica- (Fernández, 2015, pp. 503 y 504).

La violencia, por supuesto, es compleja y dependiente de la noción de daño que se sostenga. Actualmente, hay cierto consenso respecto a que la violencia no incluye únicamente el daño físico y a que el ciclo de violencia, en realidad, incluye a muchas violencias -en plural-. De acuerdo con la última Encuesta Nacional sobre la Dinámica de las Relaciones en los Hogares de México (ENDRHM) ${ }^{7}$, en 2016 el 66.1\% de las mujeres de más de 15 años había sufrido al menos un incidente de violencia emocional (49\%), económica o patrimonial o discriminación en el trabajo $(29 \%)$, física (34\%) o sexual $(41.3 \%)$ (ENDRHM, 2016, p. 8). Estas violencias abarcan distintos ámbitos: escolar, laboral, comunitario, familiar y de la pareja. Pese a estos altos porcentajes, los datos sobre la búsqueda de apoyo y de denuncia son desoladores. Por ejemplo, del porcentaje de mujeres que sufrieron violencia física y/o sexual por parte de su pareja, el $78.6 \%$ no solicitó apoyo ni presentó una denuncia. Entre las razones para no hacerlo destacan el considerar que se trató de un evento sin importancia, el miedo a las consecuencias, la vergüenza, el pensar que no la creerían o que dirían que había sido su culpa (ENDRHM, 2016, pp.39 y 40).

La noción de violencia hacia las mujeres ha sido definida por la Asamblea General de las Naciones Unidas (UNGA) como cualquier acto de violencia que se base en la pertenencia al sexo femenino que resulte o pueda resultar en daño o sufrimiento físico, sexual o psicológico, incluyendo las amenazas de tales actos, la coacción o la privación arbitraria de la libertad, sea que se desarrolle en la vida pública

\footnotetext{
7 Consultable aquí: https://www.inegi.org.mx/contenidos/programas/endireh/2016/doc/endireh2016 presentacion ejecutiva.pdf
} 
o en la vida privada ${ }^{8}$ (art. 1 UNGA). Dentro de esta categoría se incluyen, entonces, distintos tipos de conductas que vulneran a las mujeres; desde aquellas que vinculamos más fácilmente con la violencia, como el feminicidio o los delitos sexuales, hasta otro tipo de conductas que obedecen de forma más evidente a estereotipos normativos como el matrimonio infantil o la mutilación genital.

Todo lo anterior ha sido descrito para señalar que, objetivamente, las personas mexicanas están a merced de la inseguridad: la posibilidad de sufrir un daño es muy alta y la probabilidad de que dicho daño quede impune es también elevada. En este contexto, propio de la anomia social ${ }^{9}$, es de esperar que las mujeres se vean especialmente perjudicadas. Es muy probable que una mujer en México padezca algún tipo de violencia y que esta no se denuncie o no se investigue; teniendo en cuenta la naturaleza de la violencia que es ejercida sobre estas -por ejemplo, que en muchas ocasiones es llevada a cabo por personas de mucha cercanía como un familiar o por la pareja, o en contextos donde hay una gran presión por cumplir estereotipos normativos de género, hacer lo que se espera que uno haga porque se le identifica con tal o cual género-, es posible concluir que las mujeres se encuentran en una especial situación de vulnerabilidad. En este punto es interesante tener presente la reflexión de Susana Pozzolo cuando, al analizar la noción de autonomía relacional, señala cómo la vulnerabilidad de la mujer deviene de un contexto de relaciones y de factores -tanto externos como internos- y no de una vulnerabilidad intrínseca. Es decir, las mujeres no son vulnerables por el hecho de ser mujeres, sino porque el contexto relacional las vulneraliza. En palabras de la autora:

...la vulnerabilidad no es algo que depende del ser vulnerable in abstracto, sino que deriva del régimen de normas en el que ella está inmersa. Si esto es así, calificar una persona de vulnerable se vuelve potencialmente discriminatorio, pues se insistiría en hacer referencia a su ser -a su falta de- y no en atender a la responsabilidad social que conforma el régimen que la rodea, verdadera causa de la vulnerabilidad $\mathrm{o}$, mejor, de su grado de vulnerabilidad (Pozzolo, 2019, p.8).

3. La falsa oposición entre los derechos de los procesados -o los condenados- y los derechos de las víctimas

Además del daño que conlleva una conducta delictiva, hay una serie de expectativas sociales que se ven afectadas cuando se comete un crimen. $Y$ es que por más generalizada que esté la violencia, las personas no llevan a cabo sus vidas esperando ser dañadas. Por el contrario, tienen la expectativa de que las normas de mandato que proscriben determinadas conductas tendrán una cierta influencia en la decisión

8 Dicha noción es tomada como referencia en las principales declaraciones e instrumentos internacionales vinculados con el combate a la violencia y discriminación hacia las mujeres, como la Convention on the Elimination of All Forms of Discrimination against Women (CEDAW), la General Recommendation No. 19: Violence against women, la Declaration of the Elimination of Violence against Women (DEVAW), la Convención Interamericana para Prevenir, Sancionar y Erradicar la Violencia contra la Mujer o el Convenio del Consejo de Europa sobre la prevención y lucha contra la violencia contra las mujeres y la violencia doméstica.

${ }^{9}$ Este término de «anomia» fue acuñado por Émile Durkheim para referir la escisión en la relación entre los individuos y los procesos sociales, ocasionando una falta de interacción social que finalmente desemboca en la obtención de resultados sociales repetidos ineficaces. La anomia en esta concepción solo se entiende asociándola a la concepción sobre la integración social, ya que Durkheim consideró que esta integración constituye la condición para la existencia de la sociedad y la vida social; su ausencia sería la anomia y destruye la posibilidad de dicha sociedad. La integración no hace referencia únicamente a un respeto formal por el orden establecido, sino que implica una participación en la vida social que, precisamente, no se da en la anomia. En palabras de Durkheim: «Puesto que la forma definida que con el tiempo toman las relaciones que se establecen espontáneamente entre las funciones sociales es la de un conjunto de reglas, cabe decir, a priori, que el estado de anomia es imposible donde quiera que los órganos solidarios se hallan en contacto suficiente y suficientemente prolongado» (Durkheim, 1982, p. 433). 
de acción de otros, quienes, incluso no asumiendo la inalienabilidad de ciertos bienes, se verán persuadidos a no dañarlos ante la inminencia de ser responsabilizados y sancionados. Asimismo, se espera que, en caso de que dichas normas no se sigan, las autoridades estatales cumplirán la amenaza de sanción.

Al tiempo de esta perspectiva centrada en la idea de prevención y cimentada en el principio liberal del daño ${ }^{10}$, actualmente se exploran algunas aportaciones de la filosofía política -por ejemplo, del liberalismo igualitarista o del republicanismo- que subrayan, primero, el papel activo que el Estado debe tener en el combate a las desigualdades envueltas en el fenómeno criminal -es decir, que no es suficiente un ejercicio de libertad negativa, de prohibición de conductas- $y$, segundo, la importancia de repensar dicho fenómeno en el contexto de una comunidad de ciudadanos ${ }^{11}$.

Cuando el foco de discusión incluye a los miembros de la comunidad y se asienta en algo más que figuras abstractas de delincuente y de víctima, es posible analizar con mayor detalle su condición y el contexto relacional que los acompaña. Por ejemplo, las condiciones de reprochabilidad del delincuente -una revisión en términos de justicia social acerca de si el individuo ha sido tratado con la consideración y el respeto de un miembro de la comunidad- y también las necesidades y derechos de las víctimas. Desde esta perspectiva, el juicio es visto como un escenario del sistema democrático donde se emplaza al acusado a responder -dar cuenta- como ciudadano frente a sus conciudadanos por un acto que presuntamente ha cometido en contra de los valores que definen a la comunidad a la que pertenece. Lo anterior enfatiza el carácter simbólico del proceso penal para las víctimas, ya que este implica el reconocimiento de que el daño que ha sufrido es relevante y que merece ser esclarecido: la víctima ha sido devaluada como persona, ha recibido el mensaje, por parte de otro ser humano, de que no es digna de disfrutar del derecho a la no injerencia (Braithwaite y Pettit, 2002, pp. 91). Por ello, la víctima requiere de este proceso -lo que no implica, necesariamente, un resultado específico- para ver restaurado -simbólicamente- su estatus de ciudadanía. Esto quiere decir que la ineficiencia institucional no solo implica la impunidad del daño padecido, sino también el abandono de la comunidad política a la que se cree pertenecer.

Desde el siglo pasado se ha venido denunciado que el sistema de justicia ha estado volcado completamente a la parte activa del delito ${ }^{12}$. Sin embargo, esta denuncia -legítima- en ocasiones es malinterpretada como una especie de preferencia del sistema de justicia que coloca en segundo plano a la parte pasiva. En la búsqueda de visibilizar a las víctimas, esta creencia juega un papel pernicioso que conduce a concluir -erróneamente-que esto solo será posible minando los derechos

\footnotetext{
10 Este principio fue formulado por John Stuart Mill quien pretendió ofrecer un principio que rija la conducta de la sociedad con el individuo en todo lo concerniente a la coacción e intervención sobre él: «lo único que puede autorizar a los individuos individual o colectivamente para turbar la libertad de acción de alguno de sus semejantes es la protección de sí mismo. La única razón legítima que puede tener una comunidad para proceder contra uno de sus miembros es la de impedir que perjudique a los demás. No es razón bastante la del bien físico o moral de este individuo. No puede en buena justicia obligarse a una persona a hacer o no hacer una cosa porque esto fuera mejor para ella, porque le haría más feliz o porque en opinión de los demás esto sería más prudente o más justo» (1991, pp. 48 y 49).

11 Tal y como señala Antony Duff: «Los ciudadanos republicanos se ven a sí mismos como pertenecientes a una comunidad política específica, y se ven conectados a sus conciudadanos a través de las costumbres y los valores de dicha comunidad» (2015, p. 25).

12 En este sentido, George Fletcher identifica algunas grandes tendencias en el Derecho penal en el siglo $\mathrm{XX}$, presentes tanto en nuestra tradición como en el Common Law. Entre ellas, por ejemplo, (1) la crítica feminista, la cual obligó a reevaluar críticamente algunos delitos como el de violación, así como las esferas de lo público y lo privado, analizando el tratamiento discriminatorio hacia la mujer en esta área y (2) el movimiento de los derechos de las víctimas que incluyó a víctimas potenciales y concretas como un grupo de presión en la justicia penal que exigía mayor protección y participación (Fletcher, 2001).
} 
de los procesados o, en su caso, de los condenados. Lo anterior constituye una dicotomía u oposición artificiosa entre los derechos de unos y los de otros que termina por perjudicar los derechos de todos los involucrados en el proceso penal.

El problema de un -mal- razonamiento construido a partir de una falsa dicotomía es que las alternativas que propone, en realidad, no compiten entre ellas ${ }^{13}$. Además, la falsa oposición es un recurso retórico -persuasivo- esgrimido para mermar la credibilidad o el valor de una de las alternativas. El sofisma radica en que hay una exageración de una de las posturas que condena a la otra cuando la muestra como incompatible con la primera. Así, a veces el planteamiento de que el sistema de justicia debe elegir entre los derechos de las víctimas o los derechos de los procesados o de los condenados está orientado a desacreditar la protección de derechos de los segundos como si esto fuera incompatible con el estatus de víctima. A esto puede sumarse la peligrosa creencia de que es un derecho de la víctima disponer de aquel que la ha dañado ${ }^{14}$.

Algo similar a lo anterior sucede en el caso del derecho de presunción de inocencia: se presenta como incompatible sostener la inocencia del procesado hasta que se demuestre lo contrario y al tiempo sostener el estatus de víctima en lo que respecta al régimen de protección, de acompañamiento y de seguimiento del proceso penal. Como se verá en el siguiente apartado, lo que no es lógicamente posible es presumir la inocencia y presumir que la víctima ha sido dañada por la persona que se presume inocente. Nótese la diferencia entre (1) no poder presumir que $X$ es víctima de $Y$ en tanto que el proceso de asignación de responsabilidad se desarrolla y (2) no presumir que $X$ es sincera cuando se dice víctima de una conducta dañina $y$, por tanto, no brindarle ningún tipo de protección y acompañamiento.

Los derechos de las personas no compiten unos con otros. Esto no implica desconocer que hay numerosas situaciones de conflicto en las que es necesario ponderar los valores involucrados para establecer justificadamente qué es lo más justo en una situación concreta; esto es, qué valor ha de prevalecer. En este sentido, no se puede pasar por alto que en el escenario institucional la parte más débil es la que está siendo señalada como delincuente, ya que es la persona hacia la cual se dirige la coacción estatal. El resultado del juicio puede ser un castigo tan severo como la privación de su libertad; de ahí que se establezca que lo más justo en este escenario es contar con un proceso de asignación de responsabilidad que sea lo más exhaustivo posible para verificar la hipótesis acusatoria.

Lo que pretendo señalar con esta argumentación es que, pese al escenario de violencia extrema que nos aqueja, no debemos olvidar la otra cara de la impunidad: esta puede significar no solo no hacer nada ante el delito, también puede tener como manifestación perversa la arbitrariedad del poder. Es necesario recordar que el origen de un Derecho penal más garantista está, precisamente, en la lucha contra los excesos del poder estatal. La existencia de un proceso que medie entre una acusación y un castigo -así como el hecho de que hoy proscribamos ciertas prácticas de castigo- es, sin duda, una conquista de los valores ilustrados y un compromiso por construir una comunidad política democrática.

\footnotetext{
${ }^{13}$ Aquí se hace alusión a lo que Vaz Ferreira denomina la falacia de la falsa oposición. Esta falacia está tan arraigada en nuestros razonamientos que gran parte de las teorías, opiniones, observaciones, etc. de distintos ámbitos del conocimiento que se tratan como opuestas, no lo son (1979, p. 7).

${ }^{14}$ Esto forma parte de una concepción retribucionista del castigo muy básica que sostiene la existencia de una intuición ética generalizada de que la suma de dos males da como resultado un bien. Sobre esta razón se sustenta la conclusión de que los delincuentes deben ser penados en la misma proporción de su culpabilidad, independientemente de las consecuencias que esto genere.
} 
La historia nos ha mostrado en numerosas ocasiones que no es azaroso que los regímenes no democráticos debiliten las garantías en el Derecho penal. Como bien indica Carlos S. Nino, en estos regímenes el contenido de las normas penales tiende a abarcar mayores espacios de la vida de las personas; las normas también suelen ser más imprecisas en la descripción de las conductas prohibidas; las normas procesales comúnmente facilitan la labor de juzgamiento -en perjuicio de los procesados, por supuesto-; y las penas previstas bajo estos sistemas de gobierno suelen ser muy severas (Nino, 2008, pp. 13 y 14). Conviene entonces subrayar que el Derecho penal es un arma a disposición del Estado y que el establecimiento de límites a la libertad solo tiene cabida -aunque no por ello sin dificultades- en un sistema democrático y a la luz de valores liberales que ven en el individuo el único el último- sujeto ético.

Ahora bien, como señalé antes, este reforzamiento del proceso penal no ha de traducirse en la irrelevancia de las víctimas. En realidad, alimentar esta dicotomía es un ejercicio oportunista que beneficia a las autoridades responsables cuando no llevan a cabo su labor de manera diligente. Hemos de ser conscientes de que es una trampa de la propia anomia social pensar que facilitar la declaración de culpabilidad es algo que sanará a las víctimas.

En este orden de ideas, cuando las mujeres hablan de una inequidad del sistema de justicia puede que no esperen el falso antídoto de la violación de garantías del otro. Quizás esperan, entre otras cosas, un juicio justo en el que no sean revictimizadas por estereotipos normativos, en el que no esté normalizada la violencia que sufren, en el que no se les culpabilice o en el que no se desconfíe -por el hecho de ser mujeres- de su testimonio y, en general, en el que no se sientan tan abandonadas por el sistema que termine siendo una opción más apropiada desistir y enfrentar su daño en soledad. En palabras de Encarna Bodelón: «el silencio de las mujeres y su huida del sistema penal es un síntoma de que el sistema penal sigue sin poder proteger eficientemente a las mujeres que sufren violencia de género» (2014, p. 140).

\section{La presunción de inocencia y el estatus de víctima de las mujeres}

En el anterior apartado he intentado mostrar cómo no existe una genuina oposición entre los derechos de quienes están sujetos a un proceso penal y los derechos de quienes han sufrido un daño en sus bienes. Sin embargo, antes también he sostenido que el sistema de justicia penal requiere incorporar la perspectiva de género para atender adecuadamente los casos de violencia hacia las mujeres. Esto plantea cierta incoherencia: si es verdad que no existe tal oposición, que el sistema no privilegia los derechos de los procesados y que el problema de la impunidad es generalizado, ¿tiene algún sentido pensar que el género es relevante en este escenario?

En lo que sigue voy a sostener que la perspectiva de género en las investigaciones de violencia hacia las mujeres es un presupuesto para llevar a cabo adecuadamente la propia investigación. Esto es así porque los estereotipos normativos pueden jugar un papel negativo en la labor de los funcionarios, provocando sesgos cognitivos que derivan en un tratamiento a las mujeres que las violenta, y que en muchas ocasiones la presunción de inocencia del investigado se utiliza espuriamente para ocultar o justificar estos sesgos. Para ello, hay que analizar, en primer lugar, en qué consiste el derecho de presunción de inocencia y qué implicaciones tiene en la posibilidad de presumir que una mujer ha sido víctima de violencia de género. Para ello, utilizaré, nuevamente, el caso mexicano como unidad de análisis. 
En México la presunción de inocencia se hizo explícita con la reforma del sistema penal acusatorio de $2008^{15}$, quedando consagrada de forma más o menos clara en el artículo 20 de la Constitución ${ }^{16}$. En este artículo se establece como un derecho de cualquier persona imputada que se presuma su inocencia hasta que no se concluya su responsabilidad en una sentencia. Sin embargo, como ahora expondré, es difícil delimitar este derecho porque múltiples artículos de la constitución se refieren a cuestiones vinculadas con este. Por ejemplo: (1) el artículo 14 constitucional establece la inalienabilidad de los bienes de una persona en tanto no exista un juicio previo en el que se cumpla el debido proceso; (2) en el apartado A del artículo 20 constitucional, que prevé los principios generales del proceso penal acusatorio, se determina que la carga de la prueba para demostrar la culpabilidad de una persona corresponde a la parte acusadora; (3) en este mismo apartado del artículo 20 se determina que el juez solo debe condenar cuando tenga convicción de la culpabilidad del procesado. Así, en una primera revisión, es fácil observar que la presunción de inocencia es un derecho de aquel que está sujeto a un proceso penal que establece una distribución de la carga probatoria específica -no le corresponde a este probar su inocencia, sino al Estado probar su culpabilidad- y que fija un estándar probatorio concreto -la inocencia del individuo solo puede dejar de presumirse cuando existe convicción de su culpabilidad-.

Esta diversidad de dimensiones que tiene tal derecho es algo asumido por los tribunales mexicanos, reconociéndose en diversos criterios que la presunción de inocencia consiste en un derecho poliédrico que tiene diversas manifestaciones relacionadas con garantías de distintos aspectos del proceso penal. Sin embargo, como bien advierte Jordi Ferrer (2012), esta diversidad de dimensiones y facetas tiene que ser revisada para evitar solapamientos y redundancias. Queda pendiente, pues, un trabajo de depuración acerca de qué facetas sí son propias de la presunción de inocencia y cuáles se refieren más específicamente a otras garantías previstas en la Constitución. Ferrer analiza críticamente las dimensiones de este derecho que tienen más relevancia en el Derecho español ${ }^{17}$. En tanto que, como ahora señalaré, el análisis de Ferrer es aplicable a las dimensiones reconocidas en México, paso a desarrollar la clasificación que propone el autor:

(1) Dimensión extraprocesal de la presunción de inocencia. En esta dimensión, hay dos situaciones en las que esta presunción parece ser relevante: aquella en la que está implicado el poder sancionador estatal -que se refiere a las repercusiones de este principio en procesos similares ${ }^{18}$ - y en las relaciones privadas -que se refiere

\footnotetext{
${ }^{15}$ Con ello no pretendo insinuar que este derecho antes no formara parte del sistema jurídico mexicano. De hecho, hay antecedentes de él desde la Constitución de Apatzingán de 1814 que establecía que "Todo ciudadano se reputa inocente, mientras no se declare culpado» (Artículo 30). Lo que sucede es que antes de 2008 se consideraba que se trataba de un principio implícito en la constitución; así lo establecen distintos criterios jurisprudenciales, por ejemplo: «Presunción de inocencia. El principio relativo se contiene de manera implícita en la Constitución Federal». (PSCJN XXXV/2002)

${ }^{16}$ A nivel convencional, hay que subrayar que la presunción de inocencia está contemplada en el artículo 8.2 de la Convención Americana de Derecho Humanos: «Toda persona inculpada de delito tiene derecho a que se presuma su inocencia mientras no se establezca legalmente su culpabilidad. Durante el proceso, toda persona tiene derecho, en plena igualdad, a las siguientes garantías mínimas...»; y en el artículo 14.2 del Pacto Internacional de los Derechos Civiles y Políticos: "Toda persona acusada de un delito tiene derecho a que se presuma su inocencia mientras no se pruebe su culpabilidad conforme a la ley".

${ }^{17}$ El trabajo de este autor, como ya señalaba, está orientado a revisar cuáles de estas dimensiones y facetas corresponden concretamente a la presunción de inocencia. De este análisis concluye que casi todas las facetas llevan a la hipertrofia de la presunción y que las únicas que tiene sentido identificar específicamente con ella son las de la presunción como regla de trato procesal y como regla de juicio siempre y cuando se resuelva el problema de la falta de objetividad del estándar de prueba- (Ferrer, 2012, p. 185).

${ }^{18}$ En un inicio la presunción de inocencia se estableció como un principio exclusivamente aplicable al procedimiento penal. Así se estableció en la tesis aislada -superada por contradicción-: «Presunción de
} 
a las repercusiones del principio en el trato entre particulares; por ejemplo, la prohibición de que los medios de comunicación difundan información sobre la culpabilidad de un individuo sobre el que aún no hay una sentencia condenatoria ${ }^{19}-$.

(2) Dimensión procesal de la presunción de inocencia. Dentro de esta dimensión es posible identificar cuatro facetas: (2.1) La presunción de inocencia como principio informador del proceso penal: en este sentido, la presunción establece un límite para el legislador en el diseño del proceso penal y para los aplicadores del derecho en sus interpretaciones. (2.2) La presunción de inocencia como regla de trato procesal: esta faceta establece el deber de tratar al procesado como si fuera inocente hasta que, después de un proceso debidamente desarrollado, se determine su culpabilidad $^{20}$. (2.3) La presunción de inocencia como regla probatoria: esta faceta subraya que la forma de derrotar dicha presunción no es cualquier declaración judicial de culpabilidad, sino que esta debe ser el resultado de un procedimiento de asignación de responsabilidad que permita sostener que dicha persona es causalmente responsable de haber cometido la conducta ${ }^{21}$. (2.4) La presunción de inocencia como regla de juicio: esta faceta se centra en las etapas de valoración de las pruebas y de la toma de la decisión. Por una parte, establece que, en el supuesto de que no haya pruebas de la culpabilidad del individuo, este debe ser declarado inocente. Por otra parte, comprende el principio de in dubio pro reo: cuando el resultado de la valoración de la prueba sea insuficiente para satisfacer el estándar de prueba jurídicamente exigido -en el caso del proceso penal mexicano es el estándar de «más allá de toda duda razonable ${ }^{22}$ »-, la consecuencia es que no se derrota la presunción y la persona debe ser declarada inocente ${ }^{23}$ ).

Esta breve aproximación al derecho de presunción de inocencia da lugar a dos importantes conclusiones:

inocencia. Constituye un principio constitucional aplicable exclusivamente en el procedimiento penal». (SSSCJ N XC/2012 [10a.]).Actualmente podemos observar cómo dicho principio se expande a procedimientos similares, por ejemplo: «Procedimiento para el fincamiento de responsabilidades resarcitorias. Le son inaplicables los principios de presunción de inocencia e in dubio pro reo». (TCC III.7o.A.34 A [10a.]) «Presunción de inocencia. Este principio es aplicable al procedimiento administrativo sancionador, con matices o modulaciones». (PSCJN 43/2014 [10a.]). «Presunción de inocencia como regla de tratamiento del imputado en materia penal. Este derecho fundamental puede tener un efecto reflejo en otros procedimientos o ámbitos donde se establezcan consecuencias desfavorables para una persona sujeta a proceso penal». (PSSCJN CCCLXXII/2014).

${ }^{19}$ Lo anterior se corresponde con la previsión del artículo 6 de la constitución cuando establece que la manifestación de ideas puede limitarse cuando ataque la vida privada o los derechos de terceros. Igualmente, existen también criterios que abundan específicamente en ello como: «Presunción de inocencia como regla de trato en su vertiente extraprocesal. Elementos a ponderar para determinar si la exposición de detenidos ante medios de comunicación permite cuestionar la fiabilidad del material probatorio». (PSSCJN CCC/2016 [10a.]).

${ }^{20}$ Respecto a esta faceta encontramos criterios específicos como: «Presunción de inocencia como regla de trato procesal». (PSSCJN 24/2014 [10a.]).

${ }^{21}$ Por ejemplo, los siguientes criterios: «Pruebas de descargo. El juzgador debe valorarlas en su totalidad a fin de no vulnerar la presunción de inocencia del imputado». (PSSCJN CCXVII/2015 [10a.]). «Presunción de inocencia como regla probatoria». (PSSCJN 25/2014 [10a.]).

22 El Código Nacional de Procedimientos Penales establece el estándar de prueba en el tercer párrafo del artículo 402: "Nadie podrá ser condenado, sino cuando el Tribunal que lo juzgue adquiera la convicción más allá de toda duda razonable, de que el acusado es responsable de la comisión del hecho por el que siguió el juicio. La duda siempre favorece al acusado».

${ }^{23}$ En este sentido van los siguientes criterios jurisprudenciales: «Presunción de inocencia en su vertiente de estándar de prueba. Contenido de este derecho fundamental». (PSCJN VII/2018 [10a.]). «Presunción de inocencia en su vertiente de estándar de prueba. Condiciones para estimar que existe prueba de cargo suficiente para desvirtuarla». (PSCJN VI/2018 [10a.]). "In dubio pro reo. Este principio goza de jerarquía constitucional al constituir una regla implícita de la presunción de inocencia». (PSCJN VIII/2018 [10a.])«Presunción de inocencia como estándar de prueba». (PSSCJN 26/2014 [10a.]). 
(1) En realidad, no estamos ante una presunción, sino ante un principio constitucional complejo. Explicado de una manera muy simple, las presunciones establecen una relación entre hechos conocidos y hechos por conocer. Así, constituyen un deber para el juzgador al momento de valorar las pruebas: el juez debe tener por probados ciertos hechos cuando se prueban ciertos hechos previos -es decir, la estructura de la presunción es «si está probado $A$, entonces debe presumirse $\left.\mathrm{B}^{24}{ }^{2}\right)-$. Sucede que, además, en algunas ocasiones las presunciones son la formalización de máximas de la experiencia; esto es, el resultado inductivo de comprobar reiteradamente la regularidad entre dos acontecimientos ${ }^{25}$. Por ejemplo, la presunción de paternidad del hijo nacido dentro del matrimonio tiene uno de sus fundamentos en la constatación de que, en la mayoría de los casos en los que una mujer casada tiene un hijo, el padre es el cónyuge de la mujer ${ }^{26}$-por supuesto, esto también responde a que lo anterior ofrece la protección más amplia al menor-. En el caso de la presunción de inocencia esto no sucede. En primer lugar, no se cumple con la estructura básica de cualquier presunción, ya que no hay un hecho base que, de probarse, active la presunción en el momento específico de la valoración probatoria. En segundo lugar, sería muy dudoso establecer que el sustento de la presunción de inocencia es la regularidad fáctica; en realidad, en muchos delitos, las máximas de la experiencia justo nos dirían lo contrario. De aquí que antes haya señalado que parte del desconcierto que provoca este derecho puede explicarse por el hecho de que la experiencia no apoya la tesis de que en la mayoría de los casos en los que existe una acusación contra una persona esta sea inocente. Es más, en algunos supuestos existen estereotipos descriptivos con sustento estadístico para presumir lo contrario.

(2) La relevancia de la presunción de inocencia como principio fundante del Derecho penal. $Y$ es que a este derecho subyace un criterio de justicia que se ha considerado justificado para edificar este ámbito: el Derecho penal pretende castigar al culpable y absolver al inocente, pero en el caso de que no se tenga certeza de que esto se cumplirá, considera preferible absolver a un culpable que castigar a un inocente -la distribución del error-. Además, blindar la exigencia de comprobación de la hipótesis acusatoria es una especie de garantía epistemológica, en tanto que está orientada a buscar la culpabilidad verdadera -la que se corresponde con los hechosdel procesado.

Lo que podemos observar con todo lo anterior es que el derecho de presunción de inocencia se erige como una defensa contra la arbitrariedad de la autoridad. Así, el proceso penal se construye de tal forma que una persona solo puede ser declarada culpable cuando la hipótesis de la acusación ha sido constatada en la mayor medida posible. Tal y como señala Luigi Ferrajoli:

La presunción de inocencia hasta la condena definitiva es ciertamente un legado de la cultura jurídica moderna. En el proceso medieval este principio no existía; y la insuficiencia de la prueba, siempre que subsistiera una sospecha o duda respecto de

\footnotetext{
${ }^{24}$ Sobre esto también Ferrer: «... una norma que establece una presunción tiene la forma "Si está probado $A$, presúmase $B$ ". $A$ es el hecho base de la presunción. $B$ el hecho presumido. Si la presunción es iuris tantum, será posible derrotarla en caso de que se pruebe que, aunque haya ocurrido $A$ no ha ocurrido $B$, pero la no ocurrencia de $B$ deberá ser probada para derrotar la presunción. Si la presunción es iuris et de iure, una vez probada la ocurrencia de $A, B$ será presumido y aceptado en el razonamiento sin posibilidad de prueba en contrario» (2012, p. 168).

25 En muchas ocasiones las presunciones no tienen sustento fáctico, sino que se trata de reglas tendentes a proteger otro valor distinto al de verdad.

${ }^{26}$ Es importante hacer notar que este mismo ejemplo también ha sido objeto de diversas interpretaciones derivadas de los estereotipos normativos de género. Por ejemplo, verla como una presunción que "protege" el honor de la mujer casada o como una presunción que establece un mandato implícito de que una mujer solo debe tener hijos de su esposo.
} 
la culpabilidad, equivalía a una semiprueba, que conllevaba un juicio de semiculpabilidad y la semicondena a una pena más leve (2018, p. 124).

En este sentido, hacer excepciones a este derecho se vuelve cuestionable porque interfiere, primero, con una pauta fundamental de la justicia penal (dimensión normativa) y, segundo, porque hace peligrar la fiabilidad de la comprobación de la hipótesis acusatoria -dimensión epistemológica-. Es decir, «el derecho que se examina es un derecho absoluto de su titular, que deberá regir para él sin restricciones ni atenuaciones posibles, pues tiene todo el derecho a toda la presunción de inocencia, en todos los casos» (Andrés Ibáñez, 2019, p. 62).

Ahora bien, hay que examinar si lo anterior es compatible con una perspectiva de género que, precisamente, requiere de acciones afirmativas que reviertan la desigualdad estructural de las mujeres en los procesos de justicia penal. Yo sostengo que dicha compatibilidad es posible en tanto no se pretenda equiparar el derecho de presunción de inocencia -en los términos antes señalados- con un derecho de presunción de víctima del mismo alcance. El potencial de dicha compatibilidad estaría entonces, en indagar sobre qué demandas legítimas hay detrás del reclamo de que el sistema de justicia violenta institucionalmente a las mujeres. Aquí me interesa destacar dos.

(1) Una de esas demandas consiste en que la construcción de un proceso penal que procure el esclarecimiento de los hechos y la determinación de una sentencia justa no implica una descalificación de quienes se identifican como víctimas. La existencia de estereotipos normativos afecta de manera particular la experiencia de las mujeres como víctimas, especialmente debido a la larga historia de cuestionamiento de la credibilidad de su testimonio (Fernández, 2015,). La aparente inocencia del procesado no trae aparejada la duda sobre la victimización. De hecho, son las afirmaciones que hace una persona como víctima las que serán objeto de indagación, por lo que el impacto de descalificar dichas afirmaciones, además de ser re-victimizante, puede afectar por completo el objetivo de búsqueda de la verdad del proceso penal. Tener por cierto, sin ningún tipo de investigación, el relato acusatorio de la víctima implica, ciertamente, presumir contra el reo, lo cual es contrario a la presunción de inocencia. Sin embargo, hay un salto infundado entre esto último y la hostilidad hacia la víctima, la devaluación de su fiabilidad y su abandono en tanto no se concluya que, en efecto, es víctima del condenado.

(2) Otra de las importantes demandas que hay que poner de manifiesto es que el Estado debe actuar positivamente de acuerdo con el grado de vulnerabilidad de quien se dice víctima. Esto no quiere decir que en todos los casos penales hayan de tomarse medidas que impliquen un reconocimiento del estatus de víctima, que incluso puedan implicar límites a la libertad de otros. La perspectiva de género reivindica lo que Iris Young identificaba como la política de la diferencia, la cual a veces envuelve el reconocimiento de que en algunos casos es necesario «ignorar el principio de igual tratamiento a favor del principio que postula que las diferencias de grupo deberían ser reconocidas en las políticas públicas y en las políticas y procedimientos de las instituciones económicas, con el objetivo de reducir la opresión real o potencial» (2000, p. 26). En definitiva, la toma de consciencia de una estructura social de dominación en perjuicio de las mujeres justifica que las autoridades deban diferenciar la situación de este grupo y diseñar una serie de medidas de protección y acompañamiento en aquellos casos en los que acuden al sistema penal como víctimas. Es necesario subrayar que el Estado violenta a las mujeres cuando sus agentes no actúan según sus obligaciones en casos de violencias por razón de género hacia ellas, siendo omisos respecto a la toma de medidas para prevenir la violación a sus derechos y para posibilitar su acceso a la justicia (Sordo, 2018, p. 425). 
Las mujeres que han sufrido violencia y acuden a instancias judiciales se encuentran en una situación de vulnerabilidad que no puede atenderse solo manteniendo las formalidades del proceso. Hay algunos casos en los que la perspectiva de género puede motivar el asignar a una mujer la condición de víctima a efectos de recibir medidas de protección y recibir el auxilio necesario para reponer su posición. La existencia de estereotipos descriptivos con base estadística puede aportar un buen sustento en este sentido. Por ejemplo, en los supuestos en los que una mujer denuncia violencia o amenazas por parte de su pareja. Los datos sobre violencia ejercida en el ámbito de la pareja permiten sostener que es probable que, en efecto, esa mujer haya sufrido violencia y requiera del respaldo institucional para seguir el juicio y mantener su integridad intacta. Esto no constituye ningún detrimento al debido proceso ni debería predisponer al juzgador sobre la culpabilidad del procesado. Sin embargo, como he señalado ya, es necesario revisar críticamente las creencias que tenemos sobre el género. Así, aunque siga muy presente la idea de que la imparcialidad del juzgador consiste en su neutralidad, dado que ello permitirá que su deliberación parta de una página en blanco que se escriba solo con los hechos que consten en el proceso, esta idea de la jurisdicción parece muy alejada de la realidad. El desarrollo de los deberes profesionales es mucho más complejo y exige el discernimiento respecto a las creencias y motivos que subyacen a nuestras posiciones.

\section{Conclusiones}

No puede existir una presunción de victima que tenga un papel similar al que tiene la presunción de inocencia entendida como principio constitucional complejo. Sin embargo, podemos tener políticas públicas e instrumentos jurídicos que combatan la discriminación hacia las mujeres y que garanticen la protección integral de las mujeres violentadas, así como funcionarios públicos que contribuyan a paliar las desigualdades, incorporando la perspectiva de género y, con ella, la reflexión situada en torno a los intereses de las mujeres cuando se encuentran en un entorno que las hace vulnerables. Por ejemplo, actitudes como minimizar el daño sufrido, exigir mostrar huellas de violencia física, insinuar que el daño no habría sucedido si se hubiera comportado de otra manera, etc. Elena Larrauri sostiene que «incorporar la variable género implica analizar cómo esta produce alteraciones precisamente en normas e instituciones que están redactadas de forma neutral, y supone admitir la posibilidad de que los resultados para los géneros no son "idénticos"» (2009, p. 43). Así, hay que entender que ser una víctima mujer tiene implicaciones particulares, al igual que las tiene el ser una mujer procesada o castigada.

En México, desde el año 2007 se cuenta con una Ley General de Acceso de las Mujeres a una Vida Libre de Violencia en la que se reconoce la violencia institucional como aquellos actos $u$ omisiones de los funcionarios públicos que discriminan o que obstaculizan, demoran o impiden que las mujeres puedan satisfacer sus derechos. En este tema, pues, corresponde a nuestras instituciones y servidores públicos -aunque no solo a ellos- tomar consciencia y actuar sobre las desigualdades que aun afectan a las mujeres y sobre el rol que juegan los estereotipos normativos sobre cómo debe vivir una mujer, cómo debe comportarse una víctima, cómo debe responderse a la violencia, etc.- en la investigación de delitos que implican violencia hacia ellas. 
Bibliografía

Andrés Ibáñez, P. (2019). Principio de presunción de inocencia y principio de victimización: una convivencia imposible. Revista do Ministério Público, 160, pp. 59- 77.

Arena, F.J. (2016). Los estereotipos normativos en la decisión judicial. Una exploración conceptual. Revista de Derecho, vol. XXIX, n. 1, pp. 51-75.

Braitthwaite, J. y Pettit, P. (2002). Not Just Deserts. A Republican Theory of Criminal Justice, Oxford, Reino Unido: Clarendon Press.

Bobbio, N. (1991). El tiempo de los derechos. Madrid, España: Editorial Sistema

Bodelón, E. (2014). Violencia institucional y violencia de género. Anales de la cátedra Francisco Suárez, 48, pp. 131- 155.

Cortina, A. (2000). Ética mínima. Madrid, España: Editorial Tecnos, sexta edición.

Duff, A., (2015). ¿Hacia una teoría del Derecho penal? Discusiones sobre la filosofía del Derecho penal, Bogotá, Colombia: Universidad del Externado de Colombia.

Fernández Rodríguez De Liévana, G. (2015). Los estereotipos de género en los procedimientos judiciales por violencia de género: El papel del comité CEDAW en la eliminación de la discriminación y de la estereotipación. Oñati Socio-legal Series, vol. 5, $\mathrm{n}^{\circ}$. 2, pp. 498-519.

Ferrajoli, L. (2018), El paradigma garantista. Filosofía crítica del Derecho penal. Madrid, España: Editorial Trotta.

Ferrer Beltrán, J. (2012). Una concepción minimalista y garantista de la presunción de inocencia en Contribuciones a la filosofía del derecho. Madrid, España: Editorial Marcial Pons.

Fletcher, G.P. (2001). Criminal Theory in the Twentieth Century. Theoretical Inquiries in Law, 2, pp.265-286.

González Lagier, D. (2009). Emociones, responsabilidad y Derecho. Madrid, España: Editorial Marcial Pons.

Instituto Nacional de Estadística y Geografía. (2017). Encuesta Nacional sobre la Dinámica de las Relaciones en los Hogares (ENDIREH) 2016. Recuperado de https://www.inegi.org.mx/contenidos/programas/endireh/2016/doc/endireh2016 presentacion ejecutiva.pdf

Instituto Nacional de Estadística y Geografía. (2019). Censo Nacional de Gobierno, Seguridad Pública y Sistema Penitenciario Estatales 2019. Recuperado de https://www.inegi.org.mx/contenidos/programas/cngspspe/2019/doc/cngspspe 2 019 resultados.pdf

Larrauri, E. (2009). Desigualdades sonoras, silenciosas y olvidadas: género y Derecho penal. Anuario de la Facultad de Derecho de la Universidad Autónoma de Madrid, 13, pp. 37-55.

Manrique, L. (2019). Delitos de odio y motivos emocionales. Análisis Filosófico, vol. XXXIX, no. 2, pp. 191-220.

Mill, J.S. (1991). Sobre la libertad y otros escritos, Madrid, España: Ministerio de Trabajo y Seguridad Social.

Nino, C. S. (2008). Derecho penal y democracia. Fundamentos de Derecho penal. Buenos Aires, Argentina: Editorial Gedisa.

Poggi, F. (2019). Sobre el concepto de violencia de género y su relevancia para el derecho. Doxa: Cuadernos de filosofía del Derecho, 42, pp. 285-307.

Pozzolo, S. (2019). ¿Vulnerabilidad personal o contextual? Aproximaciones al análisis del derecho en perspectiva de género, Isonomía. Revista de teoría y filosofía del Derecho, 51, pp. 1-28.

Sordo Ruiz, T. (2018). Violencia institucional por razón de género contra las mujeres: casos paradigmáticos en el Estado mexicano. Miscelánea Comillas: Revista de Ciencias Humanas y Sociales, vol. 76, $\mathrm{n}^{\circ}$ 149, pp. 421-440.

Tesis Aislada núm. P. VIII/2018 (10a.) de la Suprema Corte de Justicia, Pleno, 11 de Enero de 2019. 
Tesis Aislada núm. P. XXXV/2002 (9a .) de la Suprema Corte de Justicia, Pleno, 1 de Agosto de 2002,

Tesis Aislada núm. 2a. XC/2012 (10a.) de la Suprema Corte de Justicia, Segunda Sala, 31 de Enero 2013.

Tesis Aislada núm. III.7o.a.34 a (10a.) de los Tribunales Colegiales de Circuito, 14 de Junio de 2019.

Tesis Aislada núm. P./J. 43/2014 (10a.) de la Suprema Corte de Justicia, Pleno, 30 de Junio de 2014.

Tesis Aislada núm. 1a. CCCLXXII/2014 (10a.) de la Suprema Corte de Justicia, Primera Sala, 31 de Octubre de 2014.

Tesis Aislada núm. 1a. CCC/2016 (10a.) de la Suprema Corte de Justicia, Primera Sala, 2 de Diciembre de 2016.

Tesis Aislada núm. 1a./J. 24/2014 (10a.) de la Suprema Corte de Justicia, Primera Sala, 30 de Abril de 2014.

Tesis Aislada núm. 1a. CCXVII/2015 (10a.) de la Suprema Corte de Justicia, Primera Sala, 30 de Junio de 2015.

Tesis Aislada núm. 1a./J. 25/2014 (10a.) de la Suprema Corte de Justicia, Primera Sala, 30 de Abril de 2014.

Tesis Aislada núm. P. VII/2018 (10a.) de la Suprema Corte de Justicia, Pleno, 11 de Enero de 2019.

Tesis Aislada núm. P. VI/2018 (10a.) de la Suprema Corte de Justicia, Pleno, 11 de Enero de 2019.

Tesis Aislada núm. P. VIII/2018 (10a.) de la Suprema Corte de Justicia, Pleno, 11 de Enero de 2019.

Tesis Aislada núm. 1a./J. 26/2014 (10a.) de la Suprema Corte de Justicia, Primera Sala, 30 de Abril de 2014.

Vaz Ferreira, C. (1979). Lógica viva. Moral para intelectuales. Caracas, Venezuela: Editorial Biblioteca Ayacucho.

Young, I. M. (2000). La justicia y la política de la diferencia. Madrid, España: Ediciones Cátedra. Traducción de Silvina Álvarez. 